\title{
Knowledge, Attitude and Quality of Life among Type 2 Diabetic Patients in Palestine
}

\author{
Imad Thultheen ${ }^{1}$, Ayman M. Hamdan Mansour ${ }^{2}$, Ward Zandeeq ${ }^{3}$, \\ Maysam Ewesat ${ }^{3}$, Saleem Razek ${ }^{3}$, Diana Jabareen ${ }^{3}$ \\ ${ }^{I}$ RN, MSN, PhD. Assistant Professor, Clinical Nursing. Faculty of Medicine and Health Sciences, Department of \\ Nursing An-Najah National University, Nablus, Palestine, ${ }^{2}$ PhD. Professor, School of Nursing, the University of \\ Jordan. Amman-Jordan, ${ }^{3} R N$, BSN. Research Assistant, An-Najah National University, Nablus, Palestine
}

\begin{abstract}
The purpose of this study is to investigate the association between knowledge and attitude on quality of life among diabetic patients type 2 in Palestine.

Method: A cross-sectional quantitative descriptive study that contains a sample of 120 diabetic patients were selected from Nablus hospitals and outpatient clinics to assess the level of knowledge and attitudes toward self-care and health-related quality of life.

Results: The mean score of Michigan Diabetic Knowledge Test was $8.04 \pm 2.48$ and this consider a moderate level. Of 120 diabetic patients, $27.5 \%$ had poor knowledge; $65.5 \%$ had moderate knowledge, and only 6.6 $\%$ had good knowledge. The mean for attitude score of all respondents was $125.4 \pm 10.57$ and this consider a positive attitude. There was a significant positive association between knowledge, attitude with HRQol $(\mathrm{P}=0.00)$. The mean for HRQoL score was 0.72 and it represented a moderate level of quality of life. Conclusion: Level of knowledge scores and HRQol were moderate and attitude toward the disease was positive in type 2 diabetic patients in Palestine, and there was a strong association between knowledge, attitude on HRQoL.
\end{abstract}

Keywords: Type 2 diabetes mellitus, knowledge, attitudes, health-related quality of life.

\section{Introduction}

Diabetes mellitus (DM) is a common chronic disease of global epidemic proportions and considered as a metabolic disorder that may be caused by disturbances of the body essential ingredients such as carbohydrate, fats, proteins metabolism that result from a defect of insulin secretion, its function or both ${ }^{[1-2]}$. The World Health Organization reported that the prevalence of diabetes was

\section{Correspondence Author:}

Imad N. Thultheen RN, MSN, PhD

Assistant Professor, Clinical Nursing. Faculty of

Medicine and Health Sciences, Department of Nursing

An-Najah National University, Nablus, Palestine

e-mail: imad.t@najah.edu

Tel: 00972592708853
171 million; this number is predicted to reach 300 million by $2030^{[1]}$. Findings. Nowadays International Diabetes Federation offers that each year 5,000,000 deaths are because of diabetes, which is more than the HIV/AIDS, tuberculosis, and malaria combined ${ }^{[3-4]}$. Knowledge and attitudes toward DM is the first step to be taken to formulate prevention programs for diabetes patients ${ }^{[5]}$, and the impact of education among diabetic patients will be more beneficial and more effective ${ }^{[6]}$. Health-related quality of life (HRQoL) has also been recognized as an essential health outcome, it is represented as the ultimate goal among various health outcomes. It is characterized as patient-perceived physical, emotional, and social well-being ${ }^{[7]}$. Understanding the factors that associated with poor quality of life (QOL) has a benefit in terms of promoting the physical and psychosocial burden associated with DM, eventually minimize costs, morbidity, and mortality ${ }^{[8]}$. 
Knowledge and HRQoL alone is not enough for diabetic patients to affect changes in their lifestyle, the attitude is influencing factor that affected in the relationship between knowledge and lifestyle changes. However, there are limited studies in worldwide and no studies in Palestine discussing knowledge among diabetic patients and the effects of diabetic patients' knowledge and attitudes on HRQoL. So, in this study aimed to assess present knowledge, attitudes, and quality of life among diabetic patients type 2 in Palestine.

\section{Materials and Method}

Design: A cross-sectional quantitative descriptive design was used to identify relationship between the knowledge and attitude on quality of life among diabetic patients type 2 in Palestine, using structured interview with 120 diabetics 2 patients.

Settings: Sample recruited from, hospitals and outpatients' units of Nablus, Palestine.

Sample and Population: a sample of 120 Patients aged 18 years and above, with a confirmed diagnosis of DM-II and willing to participate were included in this study. While patients who were pregnant, documented psychological problems, mental illness and who have diabetic complications renal failure, retinopathy, and diabetic foot were excluded.

Data collection Procedures: Data collection started after ensuring ethical approval from the Institutional Review Board (IRB) Committee of the College of Medicine, An- Najah University. Arabic versions of the tools were used adopting the who guideline in translation.

Instrumentation: The data collected using the following instruments

1. Demographic data that include gender, age, marital status, type of treatment, $\mathrm{HbgA1C}$, and duration of the disease.

2. Michigan diabetic knowledge test (MDKT) to asses level of knowledge, it consists of 14 multiple-choice items. Each one of the patients was asked to choose only one answer for each question, the correct answer scored one point, and the false answer scored zero. The range of the knowledge test was from 0 to 14 where the higher score of the test, the higher level of knowledge about diabetes and the zero represents the low level of knowledge about diabetes. The score of $<7$ considered as poor knowledge, 7-11 considered moderate knowledge about the disease, 12-14 considered to be a good score for knowledge.

1. Diabetic self-care profile was used from the University of Michigan. It used to assess the attitude of diabetic patients, the questionnaire contains from 33 questions. All items were scored: strongly disagree, disagree, neutralagree, agree, and strongly agree. The range of score from 33 to 165 the higher the score the positive the attitude toward diabetes care. This scale divided to 5 subscales: Need for special training to provide diabetes care, Seriousness of type 2 diabetes, Value of tight glucose control, Psychosocial impact of diabetes and attitude toward patient autonomy.

2. EuroQol five-dimensional (EQ-5D) to asses HRQOL, it consistsfrom two parts. The first part talks about self-reporting their health status, it talks about 5 dimensions: mobility, self care, usual activities, pain $\backslash$ discomfort, anxietyldepression, Each dimension contains from five levels of severity, (no problems,,slight problems,moderate problems, severe problems, unable problems). The range of the each dimension was formed from 1 to 5 , where the five is the highest score of the item known as the highest level of quality of life and the 1 represents the low level of quality of life. The second part that was conducted contain a visual analog scale (VAS), with endpoint were 0 represent bad health status and 100 represent excellent health status, that was conducted to assess and record each of the subjects about their perception on her or his quality of life.

\section{Findings:}

Demographic Characteristics: 140 patients approached and 120 questionnaires completed, with response rate of $85 \%$. the mean age (SD) was $(57.83 \pm$ 12.69) years; Mean HbAlc was $(8.41 \pm 1.55)$ and the mean duration of diabetes was $(10.24 \pm 8.28)$ years, $52.5 \%$ were female, $65.8 \%(\mathrm{n}=79)$ of the participants were married. About $60.8 \%(\mathrm{n}=73)$ had average income, About $36.7 \%(n=44)$ had a High school level of education. 
Table 1: Characteristic of the patients $(N=120)$

\begin{tabular}{|c|c|c|}
\hline Variable & Frequency & Percentages \\
\hline $\begin{array}{l}\text { Gender } \\
\text { Male } \\
\text { Female }\end{array}$ & $\begin{array}{l}57 \\
63\end{array}$ & $\begin{array}{l}47.5 \% \\
52.5 \%\end{array}$ \\
\hline $\begin{array}{l}\text { Marital status } \\
\text { Married } \\
\text { Single } \\
\text { Divorce } \\
\text { Separated } \\
\text { Widowed }\end{array}$ & $\begin{array}{c}79 \\
11 \\
9 \\
3 \\
18\end{array}$ & $\begin{array}{c}65.8 \% \\
9.2 \% \\
7.5 \% \\
2.5 \% \\
15 \%\end{array}$ \\
\hline $\begin{array}{l}\text { Economic status } \\
\text { Low income } \\
\text { Moderate income } \\
\text { High income }\end{array}$ & $\begin{array}{c}39 \\
73 \\
8\end{array}$ & $\begin{array}{c}32.5 \% \\
60.8 \% \\
6.7 \%\end{array}$ \\
\hline $\begin{array}{l}\text { Educational level } \\
\text { Elementary } \\
\text { High school } \\
\text { Diploma } \\
\text { Bachelor } \\
\text { Master } \\
\text { Another thing "illiterate" }\end{array}$ & $\begin{array}{c}41 \\
44 \\
7 \\
17 \\
2 \\
9\end{array}$ & $\begin{array}{c}34.2 \% \\
36.7 \% \\
5.8 \% \\
14.2 \% \\
1.7 \% \\
7.5 \%\end{array}$ \\
\hline $\begin{array}{l}\text { Are you under diabetic } \\
\text { treatment? } \\
\text { Yes } \\
\text { No }\end{array}$ & $\begin{array}{c}118 \\
2\end{array}$ & $\begin{array}{c}98.3 \% \\
1.7 \%\end{array}$ \\
\hline $\begin{array}{l}\text { Type of treatment } \\
\text { Medication/insulin } \\
\text { Diet } \\
\text { Insulin+diet }\end{array}$ & $\begin{array}{c}69 \\
4 \\
47\end{array}$ & $\begin{array}{c}57.5 \% \\
3.3 \% \\
39.2 \%\end{array}$ \\
\hline $\begin{array}{l}\text { How much the last } \\
\text { HbA1c } \\
<7 \text { "acceptable" } \\
\text { 7-8"good" } \\
>\text { 8"poor" }\end{array}$ & $\begin{array}{l}53 \\
16 \\
51\end{array}$ & $\begin{array}{l}44.2 \% \\
13.3 \% \\
42.5 \%\end{array}$ \\
\hline $\begin{array}{l}\text { Duration of diabetes } \\
\text { years } 5 \text { years or less } \\
6-10 \\
11-15 \\
16-20 \\
\text { More than } 20\end{array}$ & $\begin{array}{c}42 \\
42 \\
14 \\
9 \\
13\end{array}$ & $\begin{array}{c}35 \% \\
35 \% \\
11.7 \% \\
7.5 \% \\
10.8 \%\end{array}$ \\
\hline
\end{tabular}

Knowledge of DM: The mean score of the MDKT was (8.04 \pm 2.48$)$, indicating that, the patients had a moderate level of knowledge about diabetes, good knowledge was most apparent in response to the questions related to the problems that usually not associated with diabetes $(80.8 \%$ were correct) and the effect of exercise on blood glucose ( $80.8 \%$ were correct), Poor knowledge was most apparent in response to the questions related

to food that should not be used when blood glucose was low $(68.3 \%$ were incorrect). Questions regarding the effect of unsweetened fruit juice on blood sugar $(62.5 \%$ were incorrect), which foods contained the fattest also tended to be answered incorrectly ( $60 \%$ were incorrect).

Differences in knowledge and attitude related to socio-demographic characteristics: According to knowledge among female and male patients, it wasn't significant $(\mathrm{p}=0.5)$ also the attitude score wasn't significant $(p=0.081)$, The age wasn't significant for both attitude $(p=0.11)$ and knowledge score $(p=0.081)$, According to marital status, it was only significant for the knowledge score $(\mathrm{p}=0.005)$, divorced females slightly more knowledgeable toward DM (8.44 \pm 2.4$)$, according to attitude score it wasn't significant.According to economic status, it was significant both for knowledge $(\mathrm{p}=0.007)$ and attitude score $(\mathrm{p}=0.001)$, patients who had moderate-income has better knowledge $(8.54 \pm 2.39)$ and better attitude (128 \pm 9.5 ). According to the education level it was significant for the knowledge score $(p=0.01)$ the patient who has a master's degree is more knowledgeable about DM for the score of $(11 \pm 0.00)$. But the attitude score wasn't significant, for those who receive a different type of treatment, it show only significance for attitude score $(\mathrm{p}=0.014)$, and the highest score was for those who receive diet treatment (126.2 \pm 11.6 ), the knowledge score wasn't significant $(\mathrm{p}=0.107)$. According to the result of the last HbAlc, it was significant for the knowledge score $p=(0.028)$ and attitude score $(\mathrm{p}=0.02)$ the highest result was for a patient with HbA1c 7-8(128+-8.40), According to the duration of DM it was significant for the attitude score with $(\mathrm{p}=0.02)$, those who have DM between 6-10 years,

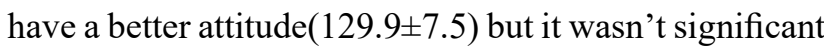
for knowledge score.

Differences in wellness scale related to sociodemographic characteristics: According to gender, there was no significance for the wellness score (EQVAS) $(p=0.88)$ and the $(E Q-5 D)(p=0.8)$. The marital status showed that there was significance in Qol, single Patients had higher scores than married $(20 \pm 5.6$ vs. 19.7 \pm 5.8$)$ for (EQ-5D). According to the economic status, it shows significance for both EQ-VAS $(\mathrm{P}=0.000)$ and EQ-5D ( $p=0.00)$, the patient who has moderate income present the highest score for wellness $(75.44 \pm 17.6)$ for EQ-VAS. The education level shows significance for the EQ-VAS $(\mathrm{p}=0.000)$ and EQ-5D $(\mathrm{p}=0.000)$, for those patients who have a master and bachelor's degree, they have the highest QOL (24 \pm 1$)$ for (EQ-5D). According to 
the duration time of DM, it show significant for the EQVAS $(p=0.012)$ and the EQ-5D $(p=0.006)$, for those who had DM duration of 5 years or less, show the highest wellness score (73 \pm 22.4$)$ for(EQ-VAS). For 5-

\section{Discussion}

In this study the mean score of knowledge was (8.04 \pm 2.48$)$, while using the Michigan diabetic knowledge test (MDKT), that was an indication of moderate knowledge. The results are is consisted with previous report ${ }^{[1,11-15]}$. Also, $60 \%$ of the patients were incorrect regarding the food that contain most fat and this consist with indicating that patients with DM-II had poor knowledge about the effect of unsweetened fruit juice on blood sugar and the food that contain most fat. In this study, we found that there is a relationship between educational level and knowledge score in which those participants with master degree got the highest score $(11+-00)$ and this consist with these studies ${ }^{[16-20]}$. It is obvious from previous studies that type 2 diabetic patients have lower scores of HRQoL than rest of populations of similar age. In this study, the mean of EQ-5D score in type 2 diabetic patients was 0.72 , which is considered a moderate score, and this consistent with other studies that reported mean EQ-5D scores as 0.74 , $0.69,0.70,0.71$ and $0.70^{[21-23]}$.

\section{Conclusion}

In this study, level of knowledge was a moderate, attitude was positive, and the level of HRQOL was also moderate level. Patients who receive diet management had high attitude score, high score of knowledge and attitude reported in 7-8 $\mathrm{HbA} 1 \mathrm{c}$. It is recommended to conduct a longitudinal study that address consequences of poor knowledge and low quality of life.

Conflict of Interest: The authors declare no conflict of interest related to publication of this article.

\section{Financial Disclosure: There is no financial disclosure.}

Ethical Clearance: the study has been approved by the ethics and research committee at An-Najah National University

\section{References}

1. Al-Aboudi, I.S., M.A. Hassali, and A.A. Shafie, Knowledge, attitudes, and quality of life of type 2 diabetes patients in Riyadh, Saudi Arabia. Journal of pharmacy \& bioallied sciences, 2016. 8(3): p. 195.

2. Adepoju, O.E., The triad of diabetes, hospitalization and work-productivity losses. 2013, The Texas A \& M University System Health Science Center.

3. Abu-Rmeileh, N.M., et al., Forecasting prevalence of type 2 diabetes mellitus in Palestinians to 2030: validation of a predictive model. The Lancet, 2012. 380: p. S21.

4. Guariguata, L., et al., Global estimates of diabetes prevalence for 2013 and projections for 2035. Diabetes research and clinical practice, 2014. 103(2): p. 137-149.

5. Hamdan-Mansour A, Marmash L, Elayyan R, Hyarat S. Difference in perception between nurses and patients related to patients' health locus of control. Int J NursPract 2014; 20: 242-249.

6. Ansari, T., et al., Assessment of knowledge, attitude, and practice of dietary pattern in patients with type 2 diabetes mellitus: a locality-based perspective study. International Journal of Medicine in Developing Countries, 2019. 3(7): p. 581-585.

7. Rubin, R.R. and M. Peyrot, Quality of life and diabetes. Diabetes/metabolism research and reviews, 1999. 15(3): p. 205-218.

8. Saleem, F., M.A. Hassali, and A.A. Shafie, A crosssectional assessment of health-related quality of life (HRQoL) among hypertensive patients in Pakistan. Health Expectations, 2014. 17(3): p. 388-395.

9. Rwegerera, G.M., et al., Health-related quality of life and associated factors among patients with diabetes mellitus in Botswana. Alexandria journal of medicine, 2018. 54(2): p. 111-118.

10. Hamdan-Mansour A. Sociodemographic correlates of somatic symptoms of older persons in Jordan. Jordan Med J 2017; 51 (3): 119-130.

11. Hamdan-Mansour AM, Al Abeiat DD, Alzoghaibi IN, Ghannam BM, Hanouneh S I. Psychosocial and sociodemographic correlates of life satisfaction among patients diagnosed with cancer in Jordan. $\mathrm{J}$ Cancer Edu 2015; 30(1): 31-36.

12. Darawad MW, Hammad S, Mosleh S, Samarkandi OA, Hamdan-Mansour A, Khalil AA, Arabiat D. Psychosocial correlates of diabetes selfmanagement practices. Iran J Public Health 2017; 46(6): 771.

13. Al Khatib A, Hamdan-Mansour A, BaniHani M. 
Theoretical perspectives of hospitalized older patients and their health-related problems and quality of care: systematic literature review. The Open Public Health Journal 2017; 10: 215-225.

14. Khatib A, Hamdan- Mansour A, Ratrout H, Alenezi A, Chahien T. Testing the effectiveness of integrated elderly care model on quality of care and health outcomes among hospitalized elderlies in West Bank. Malaysia Journal of Public Health Medicine 2020; 20(1): 82-89.

15. Mahadeen A, Hamdan-Mansour A, Halabi J, Habashneh S, Bani Kenanah A. Psychosocial wellbeing of infertile couples in Jordan. East Mediterr Health J. 2018; 4(2):169-176.

16. Mufunda, E., et al., Level and determinants of diabetes knowledge in patients with diabetes in Zimbabwe: a cross-sectional study. The Pan African Medical Journal, 2012.

17. Dreidi H, Hamdan-Mansour A. Pain, Sleep Disturbance, and Quality of Life Among Palestinian Patients Diagnosed with Cancer. J Cancer Edu 2016; 31 (4): 796-803.

18. Zowgar, A.M., M.I. Siddiqui, and K.M. Alattas, Level of diabetes knowledge among adult patients with diabetes using diabetes knowledge test. Saudi medical journal, 2018. 39(2): p. 161.
19. Hamdan-Mansour AM, Dardas LA, Nawafleh H, Abu-Asba MH. Psychosocial predictors of anger among university students. Children and Youth Services Review. 2012 Feb 1;34(2):474-9.

20. Ghannam B, Hamdan-Mansour A, Al Abaiat D. Psychosocial predictors of burden among caregivers of patients with serious mental illness in Jordan. Perspectives in Psychiatric Care. 2017;53(4):299306.

21. Hamdan-Mansour AM, Constantino RE, Farrell M, Doswell W, Gallagher ME, Safadi R, Shishani KR, Banimustafa R. Evaluating the mental health of Jordanian women in relationships with intimate partner abuse. Issues in Mental Health Nursing. 2011 Sep 23;32(10):614-23.

22. Hamdan-Mansour A, Shehadeh J, Puskar K, ElHneiti M, M Haourani E. Investigating physical, psychological and social well-being of older persons in Jordan. Current Aging Science. 2017 Aug 1;10(3):217-23.

23. Hamdan-Mansour A, Nawafeh D, Hanouneh S, Al Omari H. Psychosocial aspects of patients diagnosed with Diabetes mellitus type-II in Jordan. International Journal of Diabetes in the Developing Countries. 2015; 36:65-9. 